\title{
Costs of delayed metamorphosis: reduced growth and survival in early juveniles of an estuarine grapsid crab, Chasmagnathus granulata
}

\author{
P. Gebauer ${ }^{1}$, K. Paschke ${ }^{2}$, K. Anger* \\ Biologische Anstalt Helgoland, Meeresstation, P.B. 180, D-27483 Helgoland, Germany
}

Received 4 September 1998; received in revised form 19 November 1998; accepted 2 December 1998

\begin{abstract}
When the megalopa stage of estuarine crab species becomes competent for settlement and metamorphosis, it responds to specific chemical and physical cues from the adult environment. Delayed metamorphosis in the absence of such cues is beneficial insofar as it increases the probability of finding a suitable habitat, and it may also enhance the genetic exchange between separate populations. However, this developmental and behavioural response may incur energetic costs reducing the fitness of later life-history stages. In a laboratory investigation, we studied postmetamorphic consequences of delayed metamorphosis for growth and survival in early juvenile instars (I through V) of an estuarine grapsid crab, Chasmagnathus granulata (Dana, 1851). In competent megalopa larvae of this species, metamorphosis is induced by chemical cues from muddy substrates and conspecific adults (control treatment). After delayed metamorphosis in the absence of these cues (experimental treatment), survival and body size were significantly reduced in the first crab stage, and the duration of development to the second juvenile instar was significantly longer. Survival, moult-cycle duration, and percentage growth increments were not significantly affected in later juvenile instars. However, as a consequence of the initial reduction in development and growth, the crabs from the experimental treatment remained consistently smaller and moulted later to successive instars than in the control group. Our results indicate that delayed metamorphosis is associated with a reduced postmetamorphic fitness in an estuarine crab species. (C) 1999 Elsevier Science B.V. All rights reserved.
\end{abstract}

Keywords: Crab; Delayed metamorphosis; Postmetamorphic fitness; Settlement cues; Substratum

\footnotetext{
*Corresponding author. Fax: + 49-4725-819-369.

${ }^{1}$ Present address: Instituto de Ecología y Evolución, Universidad Austral de Chile, Casilla 567, Valdivia, Chile. ${ }^{2}$ Present address: Instituto de Acuicultura, Facultad de Pesquerías y Oceanografía, Universidad Austral de Chile, Pelluco, Casilla 1327, Puerto Montt, Chile.
} 


\section{Introduction}

Many invertebrate larvae are able to postpone their metamorphosis in the absence of characteristic environmental cues originating from the preferred habitat of settlement (Crisp, 1974). This flexibility in the timing of metamorphosis has been considered as a selective advantage, because it should enhance the probability of locating a habitat that is favourable for the subsequent survival of juvenile and adult life-history stages (Thorson, 1950; Crisp, 1974; Obrebski, 1979). However, these potential benefits might be reduced or outweighed when delayed metamorphosis has also negative consequences for postmetamorphic fitness, for example a reduction of juvenile survival or growth, or a delay in the onset of sexual maturity.

Late effects of delayed metamorphosis have been experimentally investigated in several marine invertebrate species, with negative consequences shown in particular for species with lecitotrophic larvae (for a recent review, see Hunt and Scheibling, 1997). In bryozoans (Bugula stonolifera, B. neritina), for instance, a delay of larval metamorphosis may result in retarded colony growth and development (Woollacott et al., 1989; Wendt, 1996). Reduced juvenile survival was observed in a polychaete, Capitella sp. (Pechenik and Cerulli, 1991), and reduced juvenile growth in a barnacle species, Balanus amphitrite (Pechenik et al., 1993). In species with feeding larvae, in contrast, a prolonged premetamorphic period may not normally affect the survival and growth of juveniles. Although a reduced postmetamorphic growth was measured in a spionid polychaete, Polydora ligni (Qian et al., 1990), no such effects were found in several other marine vertebrates and invertebrates with planktivorous larvae (Victor, 1986; Pechenik and Eyster, 1989; Miller and Hadfield, 1990; Cowen, 1991).

In decapod crustaceans, delayed metamorphosis or consequences thereof have been studied less extensively than in other marine invertebrates, and no consistent response patterns have been described (Hunt and Scheibling, 1997). When hermit crab megalopae were reared in the absence of a suitable snail shell, some species showed a considerable delay, while others did not respond to this cue (for a recent review, see Harvey, 1996). Also, some hermit species respond to conspecifics (Harvey, 1996) or land (Harvey, 1992). In another anomuran, the porcelain crab Petrolisthes cinctipes, the megalopa can delay its metamorphosis by up to about 3 weeks, when waterborne cues from conspecific adults are absent (Jensen, 1991). In the recruiting stages of lobsters, the availability of shelter from predation may be crucial for the timing of settlement and metamorphosis (Cobb and Wahle, 1994). Among the Brachyura, a delay of metamorphosis is common in estuarine species. This was observed in the blue crab (Callinectes sapidus), a mud crab (Rhithropanopeus harrisii), and some species of fiddler crab $(U c a)$, when chemical or physical cues from the adult habitat were absent (e.g., Wolcott and de Vries, 1994; Forward et al., 1996, 1997a,b; O'Connor and Judge, 1997; Fitzgerald et al., 1998; O'Connor and Gregg, 1998). In marine crabs, the delay of metamorphosis has been studied less intensively, although similar response patterns may be expected there too, at least in species that are strictly specialised in a particular type of habitat.

A similar response was recently shown also in an estuarine grapsid crab from South America, Chasmagnathus granulata (Dana, 1851), which lives in brackish coastal lagoons and adjacent salt marshes. Metamorphosis of the megalopa is, in this species, 
stimulated by chemical cues from conspecific adults, muddy sediments, or a combination thereof (Gebauer et al., 1998). In the present study, we investigated the effects of delayed metamorphosis on postmetamorphic fitness, measured as rates of survival and body growth in juvenile crabs.

\section{Materials and methods}

Larvae of Chasmagnathus granulata were obtained from females that were collected from Mar Chiquita lagoon, Argentina, and transported to the Marine Biological Station Helgoland, Germany. The larvae were mass-reared from hatching through the Zoea IV stage in 101 glass bottles, with gentle aeration and constant conditions of temperature $\left(18^{\circ} \mathrm{C}\right)$, salinity $(32 \%$ ) , and 12:12 h light:dark. Water and food (freshly hatched Artemia sp. nauplii) were changed daily.

In order to test for possible effects of delayed metamorphosis on later growth and survival, 300 freshly moulted megalopae were distributed among four experimental treatments with 75 individuals each: (a) muddy sediment added to the cultures; (b) seawater previously incubated with conspecific adults; (c) a piece of nylon gauze (200 $\mu \mathrm{m}$ mesh size) added as a substrate; (d) filtered $(1 \mu \mathrm{m})$ seawater only (no substrate, no incubation with adults; Gebauer et al., 1998). Each treatment comprised five replicate culture bowls with 15 megalopae reared in $390 \mathrm{ml}$ seawater. The conditions of temperature, salinity, photoperiod, feeding, and water change remained the same as described above. Freshly metamorphosed juveniles were transferred to individual plastic vials with $80 \mathrm{ml}$ seawater and gauze as a substrate, and reared through the crab V instar. Megalopae and juveniles were checked daily for mortality and moults. Carapace width (CW) and length (CL) of exuviae (only from juveniles) were measured under a Wild stereo microscope with an eye-piece micrometer to the nearest $0.02 \mathrm{~mm}$ (crab I-III) or $0.04 \mathrm{~mm}$ (later instars).

All statistical analyses followed standard techniques (Sokal and Rohlf, 1995). Between the experimental treatments, we compared measurements of moult-cycle duration, body size, and growth rate in successive juvenile instars. When data deviated significantly from a normal distribution (Kolmogorov-Smirnov test) or when variances deviated from homogeneity (Levene's median test), we used the non-parametric MannWhitney rank sum test for comparisons of mean values, otherwise Student's $t$-test. The G-test of independence was used to analyse possible effects of delayed metamorphosis on juvenile mortality. Slopes and intercepts of growth curves (intermoult period or growth increment regressed on $\mathrm{CW}, \mathrm{CW}$ vs. age) were compared by means of ANCOVA (intercepts after removal of the interaction term, if slopes did not differ significantly).

\section{Results}

Corresponding with the results of a previous study (Gebauer et al., 1998), larvae were stimulated to metamorphose by mud and conspecific adults (treatments (a) and (b)). In 
the presence of nylon gauze (treatment (c)) or filtered seawater only (treatment (d)), the larvae delayed metamorphosis by approximately 3.5 days $(31 \%)$. Since, within each of these two sets of experiments, development, survival, and growth did not vary significantly, we pooled the data into two groups, respectively. In the following, treatments (a) and (b) are thus considered together as a 'control' condition (without delay of metamorphosis), while treatments (c) and (d) together represent the 'experimental' condition (with delay).

In the absence of mud or conspecific adults, both mortality and development duration were significantly enhanced in the megalopa stage compared with the control group (Fig. 1). The same effects, only weaker, occurred also in the first juvenile crab stage. In the subsequent instars (II-V), mortality was generally low (0-4\%), without clear differences between the two treatments. Also, the moult-cycle duration (MCD) of these successive instars was similar in the two groups (Fig. 1b). Ontogenetically, the instar duration showed a gradually increasing tendency in both groups (cf. Fig. 3b).

The body size of early juveniles (carapace width (CW) in instars I and II) was significantly smaller in the treatment with delayed metamorphosis than in the control group (Fig. 2a). This difference persisted throughout the subsequent juvenile stages, although it was generally small and statistically not significant in instars III to V. The same patterns were observed also in carapace length (CL).

The CL:CW ratio was unaffected by the experimental treatment (Fig. 2b). This morphometric index decreased significantly during the course of development through successive juvenile stages. In the first crab stage, the carapace was longer than wide $(\mathrm{CL}: \mathrm{CW}=1.1)$ but, as a consequence of allometric growth, these dimensions became equal in crab II. The typical brachyuran shape (CW $>$ CL) was gradually attained in the subsequent juvenile instars.

The average size increments at ecdysis (expressed as a percentage of premoult $\mathrm{CW}$ or CL) showed no significant influence of the experimental treatments. In the moult from crab I to II, CL increased by ca. $15 \%$, and in the subsequent ecdyses by $18-21 \%$. The increment in $\mathrm{CW}$, in contrast, was maximum in the first two moults (27-28\%), but lower in later juvenile stages (22-23\%). When these increments are related to the duration of the moulting cycle (i.e. expressed as an average instantaneous growth rate in millimeters per day), the lowest rates occurred consistently in the first juvenile $(0.039 \mathrm{~mm} /$ day in $\mathrm{CW}, 0.022-0.027 \mathrm{~mm} /$ day in CL), followed by higher values in the subsequent stages (ca. $0.048-0.050 \mathrm{~mm} /$ day in $\mathrm{CW}, 0.035-0.040$ in CL). No effects of delayed metamorphosis were detected in either the percentage increments or the average daily growth rates.

When growth increments at ecdysis (in percent of premoult size) were plotted against premoult body size $(\mathrm{CW})$, a highly significant negative relationship was obtained. Statistical comparisons showed that both the slope and the intercept of the linearized regressions remained unaffected by the experimental treatment ( $Y$ values transformed logarithmically to comply with the requirements for parametric tests). Thus, all our data could be pooled to demonstrate this general relationship (Fig. 3a). The same holds true for the positive relationship between moult-cycle duration (MCD) and body size (CW) in successive juvenile instars (Fig. 3b).

A highly significant effect of delayed metamorphosis was found in the relationship 

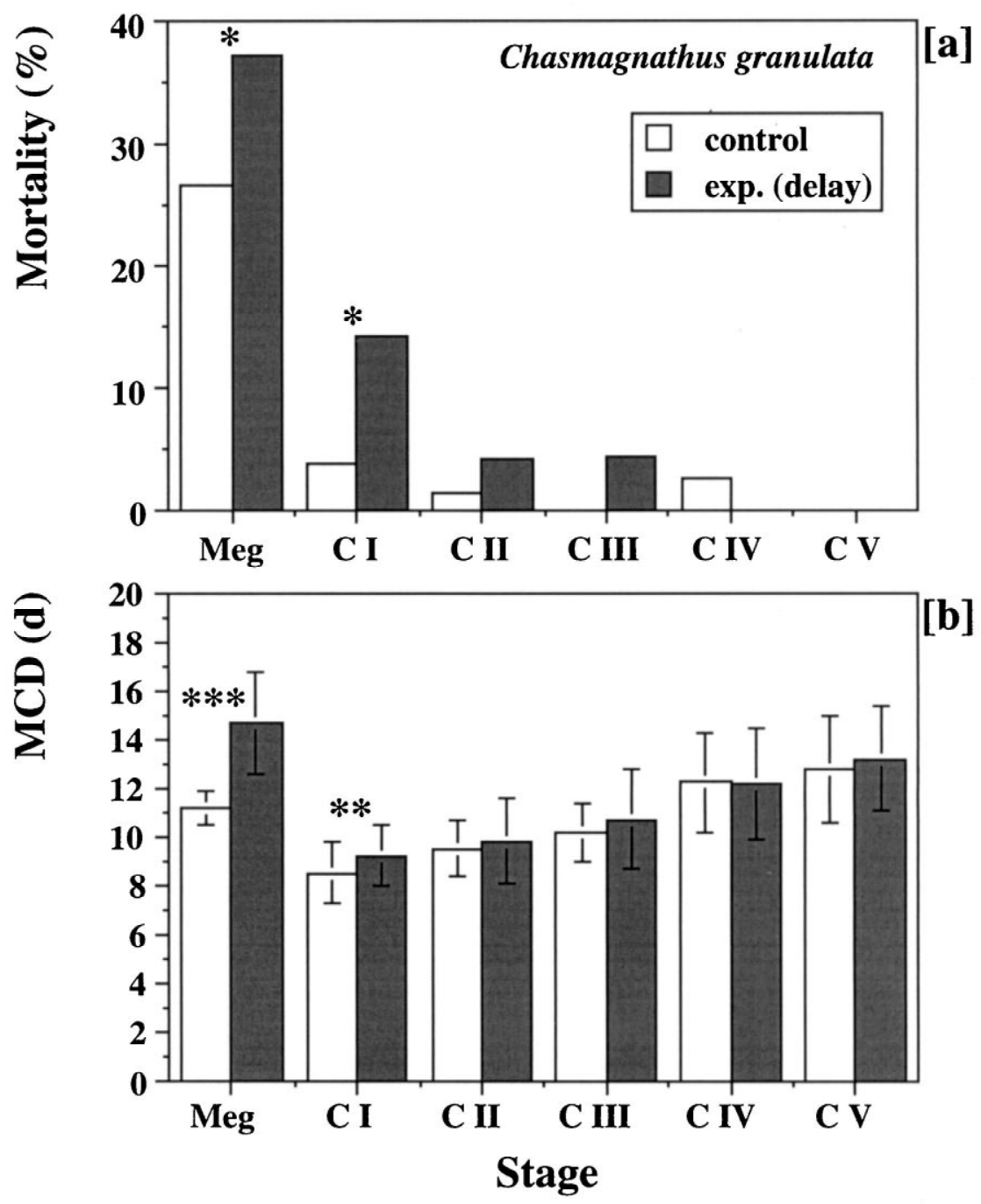

Fig. 1. (a) Mortality (percent of survivors to a given stage; initial $n=150$ per treatment). (b) Moult-cycle duration (MCD, days) in the megalopa (Meg) and juvenile crab (C) stages I-V of Chasmagnathus granulata reared in experimental (exp.) and control treatments (with or without delayed metamorphosis, respectively). $\bar{x} \pm \mathrm{SD}$; statistically significant differences marked with asteriks $\left({ }^{*} P<0.05,{ }^{*} P<0.01,{ }^{* * *} P<0.001\right)$; other differences (not marked) statistically not significant.

between juvenile body size and age. This influence of experimental treatments can be demonstrated when $\mathrm{CW}$ is plotted against time (expressed in days from the beginning of the experiment, i.e. from the beginning of the megalopa stage; Fig. 4). The individuals with an experimentally delayed metamorphosis moulted consistently later to successive juvenile instars, and in each instar they showed a slightly smaller body size than those in the control group (cf. Fig. 2a). In consequence, the slopes of the regression lines were 

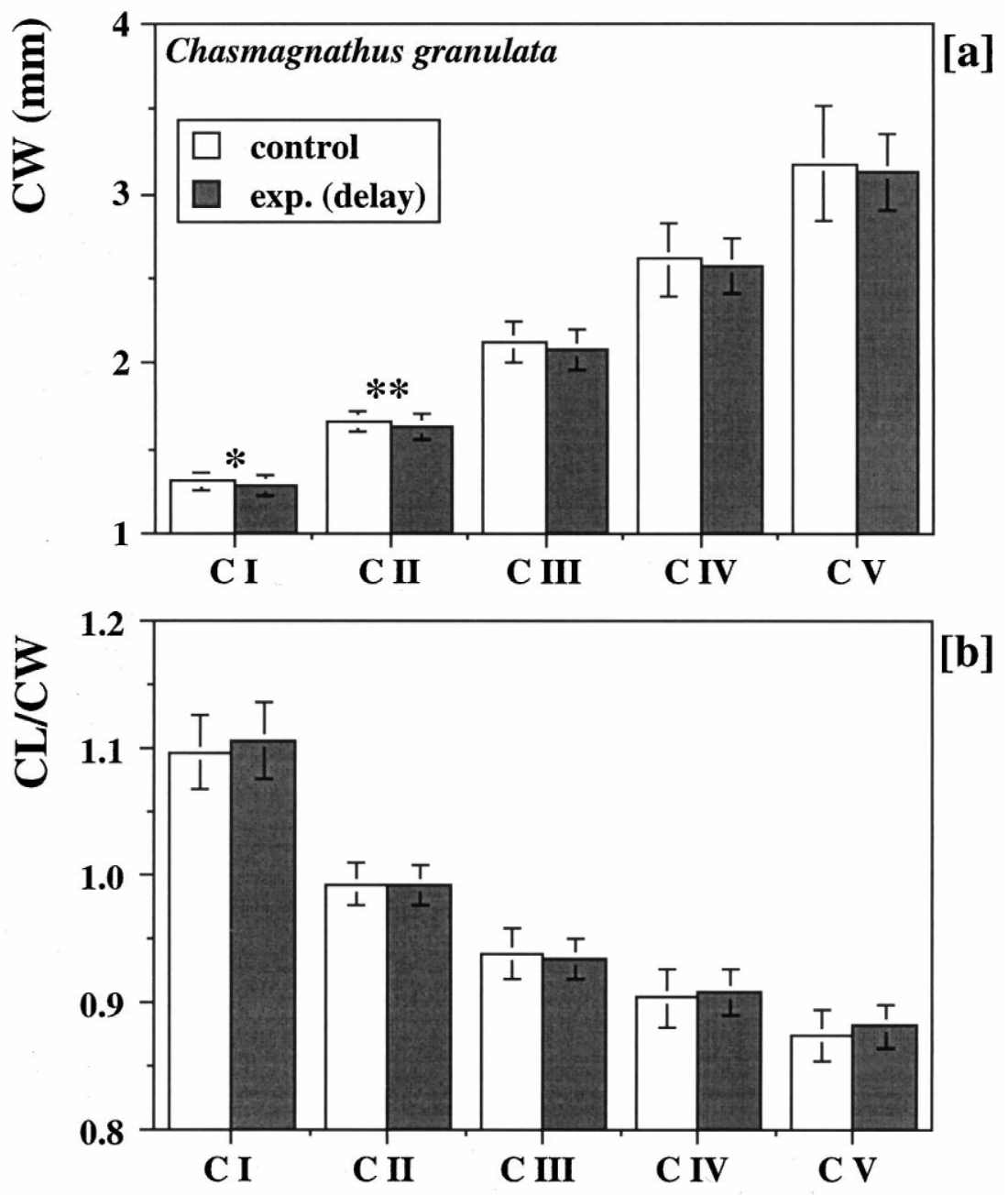

Stage

Fig. 2. (a) Carapace width (CW, mm). (b) Quotient of carapace length (CL) to carapace width (CL:CW) in the juvenile crab stages I-V of Chasmagnathus granulata reared in experimental (exp.) and control treatments (with or without delayed metamorphosis, respectively). For further explanation, see Fig. 1.

not significantly different, but the intercept parameter in the experimental group (with delayed metamorphosis) was significantly smaller than in the control $(P<0.0001)$.

A major part of this shift was caused by the delay in the time of metamorphosis from the megalopa to the first juvenile. This effect was enhanced by a significantly reduced body size in the resulting juveniles. Additionally, small (although statistically insignificant) delays of moulting occurred also in most of the later juvenile instars (Fig. 1b). The same effect (a significant parallel shift of the regression lines of CW vs. time) 

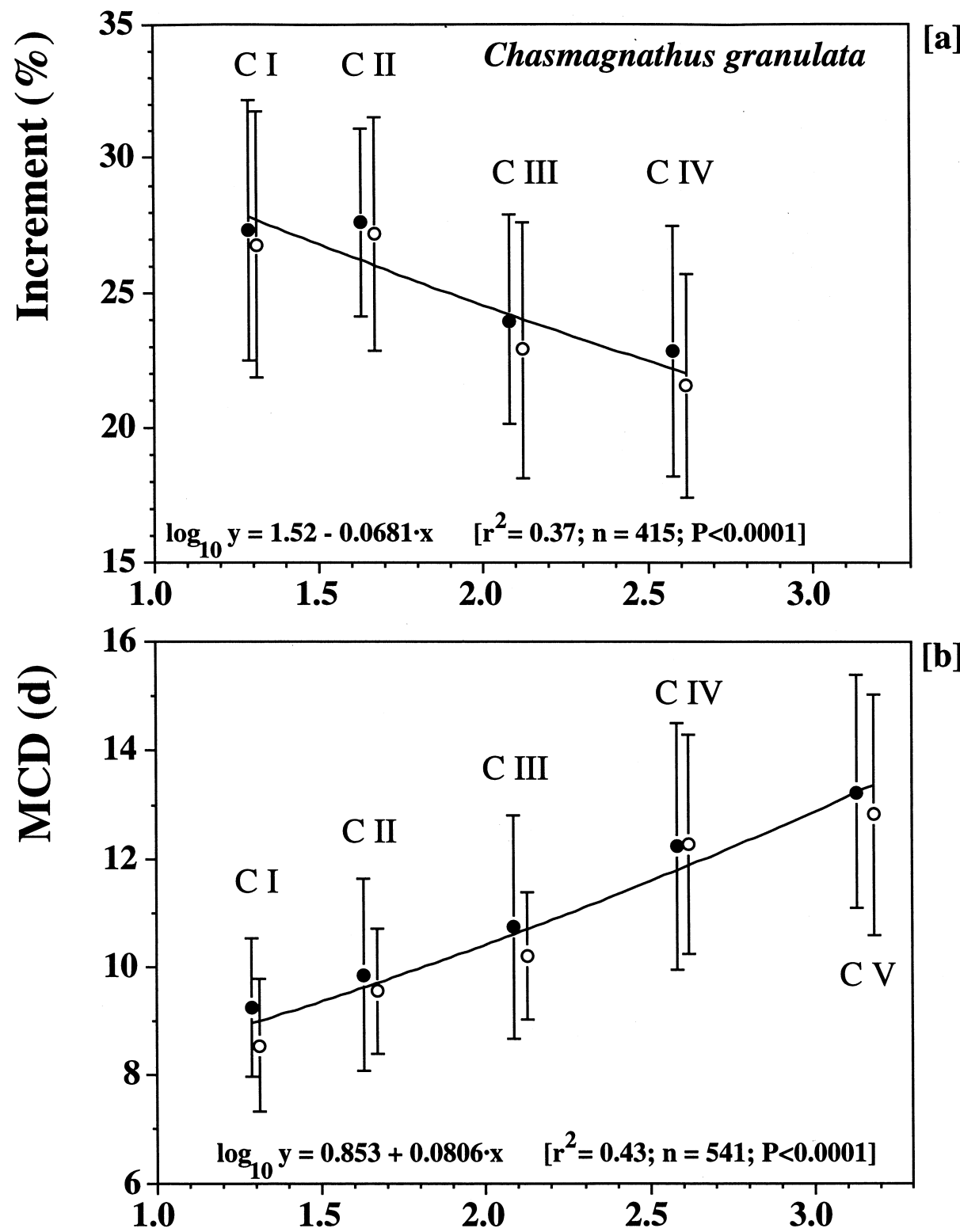

\section{CW (mm)}

Fig. 3. (a) Increment at ecdysis (percent of premoult carapace width, CW, mm) in relation to premoult CW. (b) Moult-cycle duration (MCD, days) in four successive juvenile moults (instars crab I through IV) of Chasmagnathus granulata reared in experimental (exp.) and control treatments (with or without delayed metamorphosis; filled and open plot symbols, respectively). $r^{2}$ : coefficient of determination for linearized regression equations. For further explanation, see Fig. 1. 


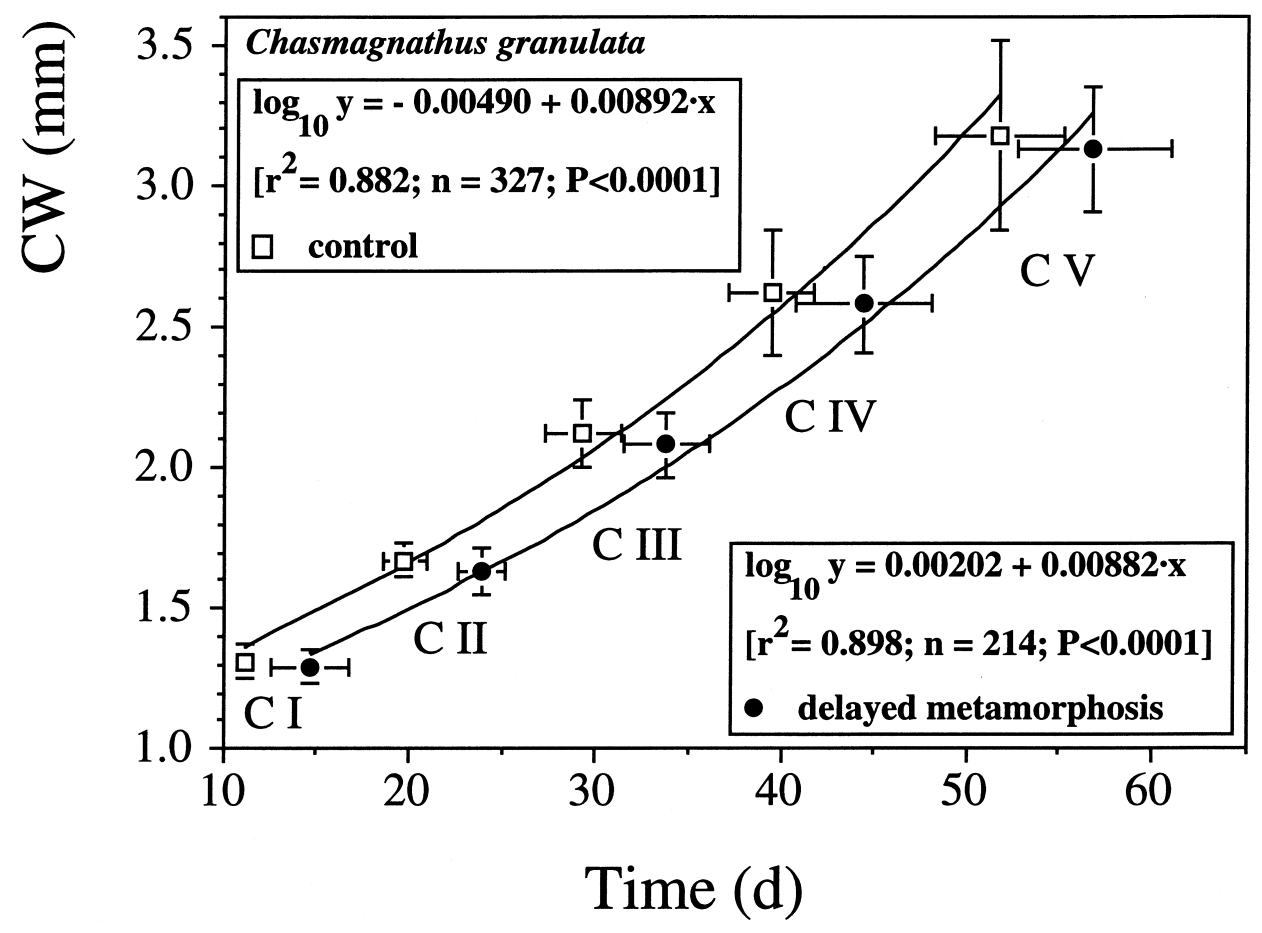

Fig. 4. Carapace width $(\mathrm{CW}, \mathrm{mm})$ as a function of time (days after the beginning of the megalopa stage) in the juvenile crab stages I-V of Chasmagnathus granulata reared in experimental (exp.) and control treatments (with or without delayed metamorphosis, respectively). For further explanation, see Figs. 1 and 3.

was obtained also when the delay in the megalopa was disregarded and only the time of juvenile development after metamorphosis was considered.

\section{Discussion}

In most marine invertebrate species investigated so far, metamorphosis cannot be delayed indefinitely. In the absence of an appropriate stimulus, the larval period is terminated either with larval death, or with a 'spontaneous' metamorphosis. The latter phenomenon, which occurred also in Chasmagnathus granulata, may be selected for by a decrease in juvenile fitness after a prolonged larval period (Pechenik, 1985, 1990). This hypothesis is supported by our present investigation, in which we measured the rates of survival, development, and body growth as independent criteria of juvenile fitness. In the absence of metamorphosis-stimulating signals, mortality and moult-cycle duration were significantly increased not only in the megalopa stage, but also in the resulting first juvenile instar (Fig. 1). In addition, the body size of early juveniles was significantly reduced after delayed metamorphosis (Fig. 2a). Hence, our data indicate 
consistently that a prolongation of the larval phase represents a condition of physiological stress.

The reduced body size of the crab I after delayed metamorphosis indicates that the megalopa lost significant amounts of energy reserves during the additional time of its development. Since the megalopa of $C$. granulata is, as in most decapod species, a feeding stage, one should not necessarily expect such losses. However, its ingestion rate may substantially decrease during the late (premoult) phase of the moulting cycle, also under constant and optimal conditions, presumably controlled by endocrine factors (Anger, 1991). During this final phase of larval development, the megalopa becomes competent for metamorphosis and may thus fully 'concentrate' on searching for a suitable habitat rather than for food. Thus, a prolonged premetamorphic period with little or no feeding activity should imply an increased utilization of internally stored reserves and, in consequence, reduce the postmetamorphic body size.

In later juvenile instars, crabs from larvae that had delayed metamorphosis were apparently not able to catch up in growth with unstressed siblings, although there were no significant late effects on survival or moult-cycle duration in the crab II or subsequent instars. Lack of compensatory growth in late juvenile stages is indicated by a small but persisting size difference between the two treatment groups. Since the individual size variability increases in later instars, the small difference in mean $\mathrm{CW}$ became statistically insignificant in instars III-V (Fig. 2a). As an additional veiling effect, size-specific survival (especially in the crab I stage) may reduce the difference in average body size between the two experimental groups. In juveniles of another crab species, Hyas araneus (Kunisch and Anger, 1984), proportionally higher mortality occurred in undersized individuals, suggesting a particularly high mortality of the weakest individuals. In our present material, however, this effect was statistically not significant.

The allometry of juvenile growth was not influenced by the preceding experimental conditions: in successive juvenile instars, the carapace length to width ratio (CL:CW) decreased clearly, independent of stimulated or delayed metamorphosis (Fig. 2b). This ontogenetic change in body dimensions is typical of brachyuran crabs (Hartnoll, 1982), which should caution against direct comparisons of differential size dimensions measured in different studies.

Due to their later moulting and smaller average size (Fig. 4), delayed individuals should be particularly vulnerable to predation, especially to intraspecific predation within a cohort of recently settled juvenile crabs (Eggleston and Armstrong, 1995; Hunt and Scheibling, 1997; Moksnes et al., 1998). In laboratory experiments, young C. granulata are highly cannibalistic, especially during ecdysis. In the presence of earlier moulted (i.e. already hardened) and larger conspecifics, survival should thus decrease as an indirect consequence of delayed metamorphosis. In addition, smaller juveniles are probably weaker competitors for food and refuge, which should further reduce their chances of survival and growth in the natural habitat (Hines, 1986).

\section{Acknowledgements}

The first author acknowledges a grant from the Biologische Anstalt Helgoland; the 
second author was funded by the Deutscher Akademischer Austauschdienst (DAAD), Bonn, Germany.

\section{References}

Anger, K., 1991. Developmental changes in the bioenergetics of decapod larvae, Mem. Queensl. Mus. 31, 289-308.

Cobb, J.S., Wahle, R.A., 1994. Early life history and recruitment processes of clawed lobsters, Crustaceana 67, $1-25$.

Cowen, R.K., 1991. Variation in the planktonic larval duration of the temperate wrasse Semicossyphus pulcher, Mar. Ecol. Prog. Ser. 69, 9-15.

Crisp, D.J., 1974. Factors influencing the settlement of marine invertebrate larvae, in: Grant, P.T., Mackie, A.M. (Eds.), Chemoreception in Marine Organisms, Academic Press, London, pp. 177-267.

Eggleston, D.B., Armstrong, D.A., 1995. Pre- and post-settlement determinants of estuarine dungeness crab recruitment, Ecol. Monogr. 65, 193-216.

Fitzgerald, T.P., Forward, R.B., Tankersley, R.A., 1998. Metamorphosis of the estuarine crab Rhithropanopeus harrisii: effect of water type and adult odor, Mar. Ecol. Prog. Ser. 165, 217-223.

Forward, R.B., De Vries, M.C., Rittschof, D., Frankel, D.A.Z., Bischoff, J.P., Fisher, C.M., Welch, J.M., 1996. Effects of environmental cues on metamorphosis of the blue crab Callinectes sapidus, Mar. Ecol. Prog. Ser. $131,165-177$.

Forward, R.B., Tankersley, R.A., Blondel, D., Rittschof, D., 1997a. Metamorphosis of the blue crab Callinectes sapidus: effects of humic acids and ammonium, Mar. Ecol. Prog. Ser. 157, 277-286.

Forward, R.B., Swanson, J., Tankersely, R.A., Welch, J.M., 1997b. Endogenous swimming rhythms of blue crab, Callinectes sapidus, megalopae: effects of offshore and estuarine cues, Mar. Biol. 127, 621-628.

Gebauer, P., Walter, I., Anger, K., 1998. Effects of substratum and conspecific adults on the metamorphosis of Chasmagnathus granulata (Dana) (Decapoda: Grapsidae) megalopae, J. Exp. Mar. Biol. 223, 185-198.

Hartnoll, R.G., 1982. Growth, in: Abele, L.G. (Ed.), Embryology, Morphology and Genetics, The Biology of Crustacea, Academic Press, New York, pp. 111-196.

Harvey, A.W., 1992. Abbreviated larval development in the Australian terrestrial hermit crab Coenobita variabilis McCulloch (Anomura: Coenobitidae), J. Crust. Biol. 12, 196-209.

Harvey, A.W., 1996. Delayed metamorphosis in Florida hermit crabs: multiple cues and constraints (Crustacea: Decapoda: Paguridae and Diogenidae), Mar. Ecol. Prog. Ser. 141, 27-36.

Hines, A.S., 1986. Larval problems and perspectives in life histories of marine invertebrates, Bull. Mar. Sci. 39, 506-525.

Hunt, H.L., Scheibling, R.E., 1997. Role of early post-settlement mortality in recruitment of benthic marine invertebrates, Mar. Ecol. Prog. Ser. 155, 269-301.

Jensen, G.C., 1991. Competency, settling behavior, and postsettlement aggregation by porcelain crab megalopae (Anomura: Porcellanidae), J. Exp. Mar. Biol. Ecol. 153, 49-61.

Kunisch, M., Anger, K., 1984. Variation in development and growth rates of larval and juvenile spider crabs Hyas araneus reared in the laboratory, Mar. Ecol. Prog. Ser. 15, 293-301.

Miller, S.E., Hadfield, M.G., 1990. Developmental arrest during larval life and life-span extension in a marine mollusc, Science 248, 356-358.

Moksnes, P.-O., Pihl, L., van Montfrans, J., 1998. Predation on postlarvae and juveniles of the shore crab Carcinus maenas: importance of shelter, size and cannibalism, Mar. Ecol. Prog. Ser. 166, 211-225.

Obrebski, S., 1979. Larval colonizing strategies in marine benthic invertebrates, Mar. Ecol. Prog. Ser. 1, 293-300.

O'Connor, N.J., Gregg, A.S., 1998. Influence of potential habitat cues on duration of the megalopal stage of the fiddler crab Uca pugnax. J. Crust. Biol. (in press).

O'Connor, N.J., Judge, M.L., 1997. Flexibility in timing of molting of fiddler crab megalopae: evidence from in situ manipulation of cues, Mar. Ecol. Prog. Ser. 146, 55-60. 
Pechenik, J.A., 1985. Delayed metamorphosis of marine molluscan larvae: current status and directions for research, Am. Malacol. Bull. 1, 85-91.

Pechenik, J.A., 1990. Delayed metamorphosis by larvae of benthic marine invertebrates: does it occur? Is there a price to pay?, Ophelia $32,63-94$.

Pechenik, J.A., Cerulli, T.R., 1991. Influence of delayed metamorphosis on survival, growth, and reproduction of the marine polychaete Capitella sp. I, J. Exp. Mar. Biol. Ecol. 151, 17-27.

Pechenik, J.A., Eyster, S., 1989. Influence of delayed metamorphosis on the growth and metabolism of young Crepidula fornicata (Gastropoda) juveniles, Biol. Bull. 176, 14-24.

Pechenik, J.A., Rittschof, D., Schmidt, A.R., 1993. Influence of delayed metamorphosis on survival and growth of juvenile barnacles Balanus amphitrite, Mar. Biol. 115, 287-294.

Qian, P.-Y., McEdward, L.R., Chia, F-S., 1990. Effects of delayed settlement on survival, growth, and reproduction in the spionid polychaete, Polydora ligni, Inv. Rep. Dev. 18, 147-152.

Sokal, R.R., Rohlf, F.J., 1995, Biometry. The Principles and Practice of Statistics in Biological Research, W.H. Freeman and Co, New York.

Thorson, G., 1950. Reproductive ecology of marine bottom invertebrates, Biol. Rev. 25, 1-45.

Victor, B.C., 1986. Delayed metamorphosis with reduced larval growth in a coral reef fish (Thalassoma bifasciatum), Can. J. Fish. Aquat. Sci. 43, 1208-1213.

Wendt, D.E., 1996. Effect of larval swimming duration on success of metamorphosis and size of the ancestrular lophophore in Bugula neritina (Bryozoa), Biol. Bull. 191, 224-233.

Wolcott, D.L., de Vries, M.C., 1994. Offshore megalopae of Callinectes sapidus: depth of collection, molt stage and response to estuarine cues, Mar. Ecol. Prog. Ser. 109, 157-163.

Woollacott, R.M., Pechenik, J.A., Imbalzano, K.M., 1989. Effects of duration of larval swimming period on early colony development in Bugula stolonifera (Bryozoa: Cheilostomata), Mar. Biol. 102, 57-63. 